\title{
From Incompatibility to Accommodation - The Journey of Taming 'Self': Guide to Perioperative Management of Solid Organ Transplantation across ABO and Rh Barrier
}

\author{
Khanna $\mathbf{S}^{1}$, Das $\mathbf{J}^{1 *}$, Kumar $\mathbf{S}^{1}$, GhoshP², Jha $\mathbf{P}^{3}$, Mehta $\mathbf{Y}^{1}$, Ahlawat $\mathbf{R}^{2}$ and Kher $\mathbf{V}^{3}$ \\ ${ }^{1}$ Institute of Anesthesiology and Critical Care, Medanta the Medicity, Gurgaon, India \\ ${ }^{2}$ Institute of Kidney and Urology, Medanta the Medicity, Gurgaon, India \\ ${ }^{3}$ Department of Nephrology, Medanta the Medicity, Gurgaon, India
}

\begin{abstract}
The fate of every organ allografting is 'rejection' if nothing is done to halt this natural process. The risks of 'hyperacute' 'accelerated acute' and 'acute' rejection have restricted scientists and clinicians over the years in performing organ transplantation within $\mathrm{ABO}$ blood group matched pairs only. Subsequent to the development in the field of immunosuppression, $A B O$ incompatible transplants have gained momentum to incorporate a significant population of end stage renal disease patients with incompatible blood group donors into the transplant program. However, optimizing the recipient for transplantation and subsequent accommodation with optimal graft function without tilting to the much easier path of rejection is a challenge. Although most of these steps come under the domain of the nephrologist, it is crucial that as the perioperative physician of a very high stake life modifying surgery, the anesthesiologist, surgeons as well as the intensivist should understand the complex process of desensitization, patient preparation and perioperative management for the best outcome. Lack of understanding about a couple of crucial considerations can jeopardize the delicate balance of immunotolerance and can prove catastrophic. The article highlights these considerations important for the perioperative clinicians along with a description of first 20 patients of blood group incompatible renal transplantation at our Institute.
\end{abstract}

Keywords: Organ transplantation; $\mathrm{ABO}$ incompatible; $\mathrm{Rh}$ incompatible; Plasma exchange; Double filtration; HLA matching; Antibody mediated rejection; Immunosuppression; Accommodation; Blood products; Coagulopathy

\section{Introduction}

"We do not feel that renal transplantation in the presence of blood incompatibility is wise". - Humes et al.

The pioneers in the field of $\mathrm{ABO}$ incompatible (ABOi) renal transplantation, Humes and colleagues lost their two initial patients in the year 1951 within a month of surgery [1]. Wordwide, the waiting list of prospective kidney transplant patients have gone up exponentially. United states 2013 data shows on an average 36000 patients are added in the kidney transplant waiting list which in itself has more than 1 lakh entries. Of these only 16,800 odd patients were operated upon in the year 2013 [2]. Such dismal scenario is mainly because of the lesser acceptance of the living donor renal allografting program in some countries and lack of blood group matched donors. The fear of ,graft rejection' and increasing the morbidity of recipient were the reasons behind the selective avoidance of transplant pairs with blood group incompatibility. Subsequently, with better understanding and developments in the field of immunology and immunosuppressive agents, improvised and selective techniques of antibody removal, combined with some landmark case series especially from Japan, today ABOi transplants have comparable outcome in terms of long term graft survival with that of compatible ones [3]. In tune with the rest of the world, ABOi renal transplantation program was started at our institute in November 2013.

\section{The ABO system and their surface antigenicity}

The ABO blood group antigens are oligosaccharide surface antigens expressed on red blood cells, vascular endothelium, renal tubules and other body tissues and body fluids [4,5]. Universal to all the blood group antigens and the sole antigen in blood group , $\mathrm{O}^{\prime}$ is the $\mathrm{H}$ antigen
[3]. Addition of specific carbohydrate determinants to the $\mathrm{H}$-antigen finally determines the blood group. Moreover, the density of A-, B- or $\mathrm{O}(\mathrm{H})$ antigen expression differentiates the various subgroups of $\mathrm{ABO}$ system which has a significant impact on antigenicity in transplant immunology. For example A1 subgroup has higher antigen expression than A2 or A3 [6] and B have lesser antigenic expression than A1 [7]. It is believed that antibodies against the other blood group types develop after birth in response to carbohydrate antigens expressed by bacteria that normally colonize the bowel [3]. With the exception of blood group 'O' as 'universal donor' and blood group 'AB' as ,universal 'recipient', any other non matched group transplantation carries the risk of antibody mediated rejection (ABMR) if the group specific antibodies are not removed from the recipient's blood beforehand.

\section{Preformed antibodies and antibody mediated rejection}

Hyper acute rejection is a possibility despite adequate cross matching and optimal pre transplant removal of anti-ABO natural antibodies [8]. In addition, acute rejection can develop during the first few weeks after ABOi transplantation via antibody-mediated humoral response. Antibody mediated rejection (ABMR) can be diagnosed based on clinical, immunologic, histopathological and serological evidences (Table 1).

*Corresponding author: Jyotirmoy Das, Consultant, Institute of Anesthesiology and Critical Care, Medanta the Medicity, 403, Aero View Heights, Sector 22, Dwarka, New Delhi; E-mail: reachjyotirmoy@gmail.com

Received: October 20, 2015; Accepted: April 05, 2016; Published: April 17, 2016 Citation: Khanna S, Das J, Kumar S, Ghosh P, Jha P, et al. (2016) From Incompatibility to Accommodation - The Journey of Taming 'Self': Guide to Perioperative Management of Solid Organ Transplantation across ABO and Rh Barrier. J Kidney 2: 122. doi:10.4172/2472-1220.1000122

Copyright: $\odot 2016$ Khanna S, et al. This is an open-access article distributed unde the terms of the Creative Commons Attribution License, which permits unrestricted use, distribution, and reproduction in any medium, provided the original author and source are credited. 
Citation: Khanna S, Das J, Kumar S, Ghosh P, Jha P, et al. (2016) From Incompatibility to Accommodation - The Journey of Taming 'Self': Guide to Perioperative Management of Solid Organ Transplantation across ABO and Rh Barrier. J Kidney 2: 122. doi:10.4172/2472-1220.1000122

\section{Preparing the donor}

ABOi transplantations have significant financial implications costing around $72 \%$ more than the conventional $\mathrm{ABO}$ compatible transplants. But still it is considered to be less expensive than maintaining renal replacement by dialysis [9]. Inspite of such a high cost intervention, the chances of antibody mediated rejection is higher. The other option that should be explained to both donor and recipient is the 'paired exchange programme', where the donors from two incompatible pairs cross donate their kidneys to compatible contralateral recipients.

\section{Perioperative Considerations}

Apart from the routine protocol of preanesthetic workup of transplant patients, special attention should be given to the following concerns:

\section{Isoglutinine titre}

The effectiveness of the 'Desensitization' protocol for $\mathrm{ABO}$ antibody removal is tested by intermittent measurements of the Isogglutinine level. Two-fold serial dilutions of the patients' serum with commercially available A/B indicator red cells are done to measure the anti-A/B antibody titers. The highest serum dilution ratio that showed $1+$ reactivity indicates the anti-A/B antibody titre (Table 2 ).

\section{The desensitisation protocol}

The preparation of the recepient involves 'Desensitization' based primarily on two principles:

1) Removal of preformed antibody by using extracorporeal techniques: Presently three techniques are primarily followed for antibody depletion - therapeutic plasma exchange, double-filtration plasmapheresis, and antigen-specific immunoadsorption. Therapeutic plasma exchange is the simple, cheap and the most commonly used modality of antibody removal. However, it has poor efficacy in terms of plasma volume processed and poor selectivity as it also depletes coagulation factors and antiviral and antibacterial immunoglobulins [10]. Double-filtration plasmapheresis and antigen-specific

\begin{tabular}{|c|c|c|}
\hline Parameter & \multicolumn{1}{c|}{ Findings } \\
\hline Clinical & Decrease in urine output and rise in creatinine levels \\
\hline Immunologic & - & $\begin{array}{l}\text { C4d deposition in the peritubular capillary } \\
\text { Presence of immunoglobulin and/or } \\
\text { complement in fibrinoid necrosis }\end{array}$ \\
\hline Histopathological & - & $\begin{array}{l}\text { Peritubular capillary and /or glomerular } \\
\text { leucocyte infiltration } \\
\text { Glomerular and arterial thrombi with arterial } \\
\text { fibrinoid necrosis } \\
\text { Acute tubular injury }\end{array}$ \\
\hline Serological & - & Circulating antidonor antibodies \\
\hline
\end{tabular}

Table 1: Clinical, immunologic, histopathological and serological evidences.

\begin{tabular}{|c|c|c|}
\hline Donor Blood Group & $\begin{array}{c}\text { Recipient Blood } \\
\text { Group }\end{array}$ & Testing Performed (Igm And lgg) \\
\hline AB & O & Anti A, Anti B \\
\hline B & O & Anti B \\
\hline A & O & Anti A \\
\hline AB & B & Anti A \\
\hline A & B & Anti A \\
\hline AB & A & Anti B \\
\hline B & A & Anti B \\
\hline
\end{tabular}

Table 2: Testing performed for antibody levels as per blood group incompatibility. immunoadsorption are selective techniques of antibody removal [11]. These extracorporeal techniques of antibody removal are on top of the routine dialysis schedule.

2) Inhibition of ongoing Ab production: by splenectomy and use of immunosuppressive drugs.

Splenectomy was previously thought to be an important modality to specifically and irreversibly deplete memory B cells, thereby reducing antibody producing B lymphocytes but has lately come under the scanner. A growing body of evidence disapprove splenectomy in $\mathrm{ABO}$ recepients [12] and in turn prefer anti-CD20 monoclonal antibody (Rituximab) induction. Rituximab inhibits B-cell proliferation and induces cellular apoptosis (chemical splenectomy). It has its effects on Pre B, B and Memory B cells (precursor of plasma cells which contribute to $\mathrm{Ab}$ production). However, a significant concomitant reduction in immunoglobulin level can render these patients susceptible to infection and wound related complications.

Preoperative use of intravenous immunoglobulin: Helps in downregulation of the antibody mediated immune response. Immunoglobulin administration generally follows every session of plasmapheresis.

A typical desensitization scheme is depicted in Figure 1 below.

Other immunosuppressives: Similar to $\mathrm{ABO}$ compatible transplant, 'Triple immunosuppression' consists of Calcineurin inhibitors (cyclosporine and tacrolimus), antimetabolites (mycophenolate mofetil and azathioprine) and low-dose steroids. A fourth agent is frequently used in the form of monoclonal or polyclonal antibody agents (anti-CD25 antibody or antithymocyte globulin) during the induction period. It is important to ensure that the recipient takes all the immunosuppressants on time, especially the preoperative dosage. Knowledge of the immunosuppressant protocol and especially precautions associated with the intraoperative use of interleukin 2 antagonist or antithymocytic globulin is important for their safe administration.

\section{Time of last session of extracorporeal antibody removal technique}

Knowledge of the last session of both extracorporeal antibody removal technique and dialysis are important along with the post dialysis fresh blood reports and pre transplant isogglutinine titres. Every institute has their own target for pre transplant isogglutinine titre. In our institute, we aim for a target of $\leq 1: 8$. Some patients may show a significant rebound increase in isoagglutinine titers despite multiple sessions of plasmapheresis preoperatively. These so called 'immunologic high responders' $[4,13]$ are poor candidates for ABOincompatible transplantation. As already described extracorporeal techniques of antibody removal (except immuneadsorbtion) have the disadvantage of concomitant removal of protective coagulation factors and antibodies making the patient vulnerable to bleeding diathesis and infections [10]. The maintenance of high level of antiseptic precautions throughout, adequate arrangement of blood products, meticulous surgical haemostasis are of utmost importance as the intraoperative blood loss may be higher compared to non-plasma exchange patients.

\section{Immunosuppressive effects of stress response and anesthesia}

$\mathrm{ABO}$-incompatible transplantation requires more intense and costly immunosuppressive therapy [14-16]. Moreover, perioperative anxiety and stress response are potentially immunosuppressive. It is important to understand that such immunosuppression can jeopardize 
Citation: Khanna S, Das J, Kumar S, Ghosh P, Jha P, et al. (2016) From Incompatibility to Accommodation - The Journey of Taming 'Self': Guide to Perioperative Management of Solid Organ Transplantation across ABO and Rh Barrier. J Kidney 2: 122. doi:10.4172/2472-1220.1000122
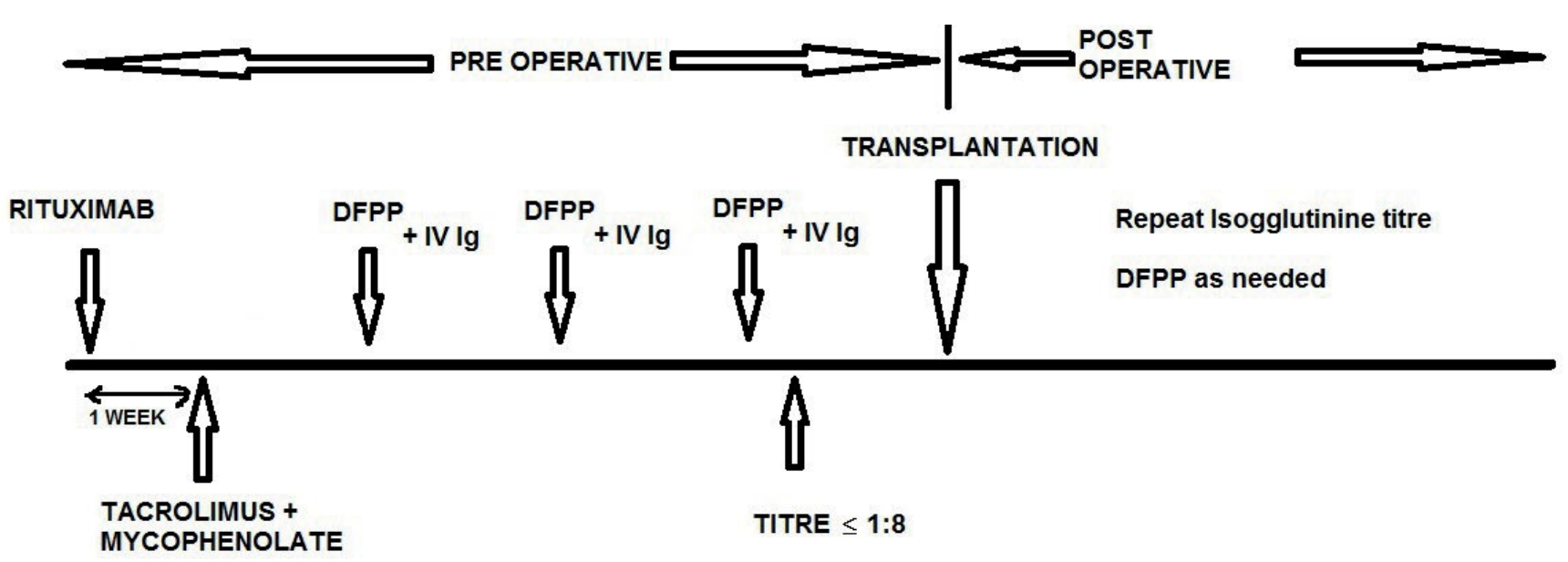

DFPP : Double fitration plasmapheresis

\section{If the initial titres is $\leq 1: 8$, than transplantation is carried out straightway 2 weeks after Rituximab and 1 week after tacrolimus and mycophenolate induction without any antibody removal.}

Figure 1: Antibody removal and desensitisation protocol follwed at our institution.DFPP: Double Filtration Plasmapheresis; IVIg: Intravenous Immunoglobulin.

the already maximally suppressed B and T cell immunity in transplant recipients and therefore is undesirable. To maintain homeostasis every effort should be made to reduce the immunomodulating influence of perioperative stress. Preoperative anxiolysis, smooth conduct of anesthesia and regional block techniques, use of potentially immunostimulating regional analgesia and avoidance of conditions known to reduce immunity (eg: high dose opioids, postoperative pain, hypothermia) are some of the steps towards that goal.

\section{Perioperative blood product transfusion}

Blood products should be arranged as per the compatibility profile as depicted in the table below (Table 3).

Use of a blood product not tallying with the above list can induce severe antigen antibody reaction and seriously effect the graft outcome.

\section{Postoperative Considerations}

A lowered threshold for rejection alarm, repeat follow up of isogglutinine titre, safe use of blood products, strict asepsis are some of the considerations which should be strictly followed over and above the usual issues of a routine ABO compatible transplant. In our institution we repeat the antibody titre on the $1^{\text {st }}$ post operative day. If the measurement is within recommended range of $1: 8$ and the graft is functioning well, then the titre is repeated daily for 1 week. Thereafter, titres are measured twice weekly for two weeks and plasmapheresis is done in case there is persistent rise in antibody titre.

In a transplant patient adequate post operative pain relief is of utmost importance to break the cycle of pain induced sympathetic over activity and the subsequent vasoconstriction of the graft vessels. However, in an ABOi recipient prepared by plasmapheresis, the possibility of coexisting coagulopathy should be kept in mind and the safety of insertion of a catheter for central neuraxial regional analgesia should be evaluated on a case to case basis. Other modalities of postoperative pain relief like intravenous opioid by infusion or patient controlled analgesia are good options.

\section{Considerations in a $\mathrm{Rh}$ incompatible transplantation}

Two main considerations during $\mathrm{Rh}$ incompatible ( $\mathrm{Rh}$ positive donor and $\mathrm{Rh}$ negative recipient) transplantation are: blood product management and RhIG prophylaxis especially in a female patient. Packed RBC should be Rh-compatible with the recipient's blood type and platelet concentrate, fresh frozen plasma and cryoprecipitate should be Rh-compatible with the donor [17]. This can sometimes be a limiting factor in prior arrangement of blood products for a rare blood and $\mathrm{Rh}$ group patient. Although an immunosuppressed patient is less likely to mount an effective response to $\mathrm{RhD}$ antigen, still prophylactic RhIG can be considered in case of $\mathrm{Rh}^{+} \mathrm{RBC}$ transfusion especially in female patients (of any age) who may get future exposure or might have been previously exposed to $\mathrm{Rh}^{+} \mathrm{RBCs}$ (via transfusion or pregnancy) prior to the free availability and protocolisation of perinatal $\mathrm{Rh}$ immune globulins.

\section{The process of accomodation}

Once the acute postoperative phase is over, anti donor blood group antibodies start rising in the recipient despite the use of immunosuppressive agents. But, even then the graft continues to function normally and exhibits apparent resistance to humoral rejection even in the presence of antibodies directed against the graft endothelium [18]. This phenomenon is called, accommodation' $[19,20]$. This is because of the long term natural protection that makes ABOi transplants a possibility. Although precisely not known, various theories have been postulated for the mechanism of accommodation:

- An active change in endothelial cell physiology or phenotype

- Expression of "protective gene" products that render the graft resistant to the effects of complement and other activating stimuli $[21,22]$

- Inhibition of inflammation by complement split products like $\mathrm{iC} 3 \mathrm{~b}$ and $\mathrm{C} 3 \mathrm{a}$ 
Citation: Khanna S, Das J, Kumar S, Ghosh P, Jha P, et al. (2016) From Incompatibility to Accommodation - The Journey of Taming 'Self': Guide to Perioperative Management of Solid Organ Transplantation across ABO and Rh Barrier. J Kidney 2: 122. doi:10.4172/2472-1220.1000122

Page 4 of 4

\begin{tabular}{|c|c|c|c|c|c|c|c|}
\hline Recipient & Donor & PRBC & FFP $1^{\text {st }}$ choice & FFP $2^{\text {nd }}$ choice & Platelets $1^{\text {st }}$ choice & Platelets $2^{\text {nd }}$ choice & Remarks \\
\hline $\mathrm{O}$ & A & $\mathrm{O}$ & $A B$ & A & $A$ & $A B$ & \multirow{7}{*}{$\begin{array}{l}\text { - First choice FFP is of AB group } \\
\text { - PRBC is of either recipient's } \\
\text { own blood group or O group }\end{array}$} \\
\hline $\mathrm{O}$ & $B$ & $\mathrm{O}$ & $A B$ & $B$ & $B$ & $A B$ & \\
\hline $\mathrm{O}$ & $A B$ & $\mathrm{O}$ & $A B$ & A & $A B$ & A & \\
\hline A & $B$ & A or $O$ & $A B$ & A & $A B$ & $B$ & \\
\hline A & $A B$ & A or $\mathrm{O}$ & $A B$ & A & $A B$ & $A$ & \\
\hline $\mathrm{B}$ & A & $\mathrm{B}$ or $\mathrm{O}$ & $A B$ & $B$ & $A B$ & A & \\
\hline $\mathrm{B}$ & $A B$ & $\mathrm{~B}$ or $\mathrm{O}$ & $A B$ & $\mathrm{~B}$ & $A B$ & B & \\
\hline
\end{tabular}

Table 3: Recommended use of blood products in ABOi transplantation. PRBC: Packed Red Blood Cell; FFP: Fresh Frozen Plasma.

- Up regulation of various cytoprotective mechanisms by endothelial cells

- Disruption of normal signal transduction

- Attenuation of cellular adhesion

- Prevention of apoptosis

\section{ABOi Organ Transplantation in Children}

Long term data so far have suggested that younger recipients ( $<15$ years of age) have excellent outcome following ABOi renal transplantation with $100 \%$ graft survival rate at 1 year and $95 \%$ at 2 to 9 years [4]. This is probably because of the immaturity of the immune system. Reported infectious complications are also few in the pediatric population $[15,23]$. However, post-transplant, viral infections (Cytomegalo virus, Pneumocystis carinii, Listeria monocytogenes, and Aspergillus fumigatus) are common [24]. The risk of primary cytomegalo virus (CMV) infection in children following transmission from a CMV-positive donor warrants appropriate prophylaxis (antiviral chemotherapy) preoperatively $[25,26]$.

\section{Conclusion}

Increasing numbers of case series and evidences show that $\mathrm{ABO}$ kidney transplantation is a feasible option and more and more centers are inculcating it into their transplantation program. Although newer age immunosuppressants and antibody removal techniques have made it possible, still transplantation across $\mathrm{ABO}$ barrier should be considered as 'high risk' in terms of graft acceptance and function. Needless to say it demands multispecialty involvement and thorough understanding of the topic. But unfortunately, not much information and scientific data are available addressing the perioperative management concerns of such patients especially catering to the requirements of non nephrologists who otherwise play significant role in the transplantation program. We think our article will help in adding some information in this field.

\section{References}

1. Hume DM, Merrill JP, Miller BF, Thorn GW (1955) Experiences with renal homotransplantation in the human: report of nine cases. J Clin Invest 34: 327-382.

2. National kidney foundation (2016) Organ donation and transplantation statistics.

3. (2002) ABO-Incompatible Kidney Transplantation in Children. Graft 5: 430

4. Takahashi K (2001) ABO-incompatible kidney transplantation. Amsterdam: Elsevier Science BV.

5. Bariety J, Oriol R, Hinglais N, Zanetti M, Bretton R (1980) Distribution of blood group antigen $\mathrm{A}$ in normal and pathologic human kidneys. Kidney Int17: 820-826.

6. Reed E, Moore BP (1964)A new variant of blood group A. Vox Sang 9: 363-366.

7. Breimer ME, Molne J, Norden G, Rydberg L, Thiel G (2006) Blood group A and $B$ antigen expression in human kidneys correlated to A1/A2/B, Lewis, and secretor status. Transplantation 82: 479.
8. Toma H, Tanabe K, Tokumoto T (2001) Long-term outcome of ABO-incompatible renal transplantation. Urol Clin North Am 28: 769-780.

9. Schnitzler M (2006) ABO-incompatible living donor transplantation: is it economically "compatible"? Transplantation 82: 168-169.

10. Crew RJ, Ratner LE (2010) ABO-incompatible kidney transplantation: current practice and the decade ahead. Current Opinion in Organ Transplantation 15: 526-530.

11. Genberg H, Kumlien G, Wennberg L, Tydén G (2010) Isoagglutinin adsorption in ABO-incompatible transplantation. Transfus Apher Sci 43: 231-235.

12. Sonnenday, Gloo R, Takahashi (2007) Living Donor Transplantation.

13. Shishido S, Asanuma $H$, Tajima E, et al. (2001) ABO-incompatible living-donor kidney transplantation in children. Transplantation 72: 1037-1042.

14. Grim SA, Pham T, Thielke J, Sankary H, Oberholzer J, et al. (2007) Infectious complications associated with the use of rituximab for $A B O$-incompatible and positive cross-match renal transplant recipients. Clin Transplant 2: 628-632.

15. Warren DS, Zachary AA, Sonnenday CJ, King KE, Cooper M, et al. (2004) Successful renal transplantation across simultaneous $A B O$ incompatible and positive crossmatch barriers. Am J Transplant 561-568.

16. Dean PG, Gloor JM, Stegall MD (2005) Conquering absolute contraindications to transplantation: positivecrossmatch and $\mathrm{ABO}$-incompatible kidney transplantation. Surgery 137: 269-273.

17. Choi J, Seo $\mathrm{H}$, Jeong SM, Hwang GS (2013) Anesthetic experience of combined $\mathrm{ABO}$ - and $\mathrm{Rh}$-incompatible living donor liver transplantation between an O Rh- recipient and a B Rh+ donor. Korean J Anesthesiol 65: 480-481.

18. Alexandre, Cardella, Reding (2000) Humoral rejection.

19. Lin SS, Hanaway MJ, Gonzalez-Stawinski GV, Lau CL, Parker W, et al. (2000) The role of anti-Galalpha1-3gal antibodies in acute vascular rejection and accommodation of xenografts. Transplantation 70: 1667-1674.

20. Lin Y, Soares MP, Sato K, Csizmadia E, Robson SC, et al. (2000) Long-term survival of hamster hearts in presensitized rats. J Immunol 164: 4883-4892.

21. Bach FH, Ferran C, Hechenleitner P, Mark W, Koyamada N, et al. (1997) Accommodation of vascularized xenografts: expression of "protective genes" by donor endothelial cells in a host Th2 cytokine environment. Nat Med 3: 196-204.

22. Brouard S, Blancho G, Moreau A (1998) Long-term survival of hamster-torat cardiac xenografts in the absence of a Th2 shift. Transplantation 65: 1555-1563.

23. Ohta T, Kawaguchi H, Hattori M, Takahashi K, Nagafuchi H, et al. (2000) ABOincompatible pediatric kidney transplantation in a single-center trial. Pediatr Nephrol 14: 1-5

24. Fine R, Bajaj G (2001) Renal transplantation in children. In: Morris $P$ (ED.) Kidney transplantation: principles and practice. (5th edn), PA: WB Saunders, Philadelphia, 604-657

25. Bock G, Sullivan EK, Miller D (1997) Cytomegalovirus infections following renal transplantation-effects on antiviral prophylaxis: a report of the North American Pediatric Renal Transplant Cooperative Study. Pediatr Nephrol 11: 665-671.

26. Gagnadoux M, Niaudet P, Bacri JL (1993) Nonimmunological risk factors in pediatric renal transplantation. Pediatr Nephrol 7: 89-95. 